\title{
On Adding Cultural Contents to English Teaching
}

\author{
Yanping Huang \\ Dezhou University, Dezhou, China \\ Email: xiongmei_yan@163.com
}

\begin{abstract}
In order to put the achievement of Cross-cultural Communication reaches into foreign language teaching practice as soon as possible and to increase the cultural contents to English teaching, this paper would put forward the following three respects: Why to increase the contents of culture in English teaching, Which contents of culture should be added and how to increase cultural contents to English teaching.
\end{abstract}

Index Terms - cultural contents, English teaching, practical foreign language teaching, teaching reform, culture factor

Since the eighties of the 20th century, a lot of linguists and foreign language workers have begun to research on the relations between culture and languages and the influence produced by communication and culture in order to solve the problem between different cultures. At present, more gratifying progress have been made. Therefore it gradually formed a new developing multi-subjects and crossing nature discipline-Cross-cultural Communication. Though there is no direct relationship between the rise and development of Cross-cultural Communication and foreign language teaching, its research results have a great impact on foreign language teaching. Especially in recent years, Cross-cultural Communication has already become a hot issue in foreign language teaching in china's education circle. If the researches in the past few years were staying at the theory aspect, now it has already entered into the field of foreign language teaching. At the same time, it has aroused the attention of more and more foreign language educators. In order to put the achievement of Cross-cultural Communication into foreign language teaching practice as soon as possible and to increase the cultural contents into English teaching, here I am going to put forward the following three respects to defence my point, hoping to discuss with those who are interested in this field.

\section{Why to AdD THE CONTENTS OF CULTURE TO ENGLISH TEACHING?}

\section{A. To Meet the Need of the Social Development in the 21st Century.}

Economic globalization and the information integrations have made the earth become smaller and smaller, which also formed a global village. We are not just the citizens of China, but also the global villagers. The future of the earth and the destiny of the whole world have already connected us tightly with people of other countries.

China's entering into the WTO indicated that the reform and opening-up of China had reached a new stage. As the economy of China is included in the track of the international economy progressively and various kinds of cross-cultural communications are made by people more frequently day by day, we have to face and solve the following issue. First, improving the level of foreign language rapidly, to strengthen the consciousness and the global idea. Secondly, understanding the whole world and the culture all over the world have already become one of the urgent tasks which all trades and professions face. Meanwhile it is a new demand and a new goal that put forward the foreign language teaching of our country with the development of the society.

\section{B. To Meet the Need of Practical Foreign Language Teaching in China.}

Language is a carrier of the culture. Any kind of existing language implies the cultural intention of the people who use this kind of language in the course of long-term historical development. Only when one acquaints himself with those imply in the cultural intension behind this kind of language, can he "return the flesh and blood of the language and comprehend the concrete meaning of the cultural issues"(China, Liguangkun). Then we can understand the language thoroughly and therefore use it as a tool properly.

In view of the above, Chinese linguistic Huwenzhong proposed that to study a kind of language can develop two kinds of abilities at the same time: Ability of the language (linguistic competence) and social ability (social competence or cultural ability). Then gradually form the ability of cross-cultural communication.

\section{To Meet the Need of Chinese English Teaching Reform}

In a sense, the ability of using English synthetically lower and in the lack of knowledge of foreign country culture are two major matters existing in China's English teaching at present. As for the former one, we are making great efforts to improve by every possible means; as for the latter one, we have just begun our work and it is no doubt that we should spare much more effort to probe into it.

As we can't fully understand the culture of foreign country especially those of the English speaking country, most of the Chinese who are learning English short of the insight into the differences between English and Chinese culture. The negative results are as following: On one hand, they fail to understand the language phenomenon that imply the cultural 
intension accurately and even misunderstand them. On the other hand, while using these languages in cross-cultural communication, they often express what they thought according to the habit of the Chinese culture which would lead to unable to use English appropriately. To make matters worse, they even enable to exchange ideas with the foreigners, which then would obstruct communication and cooperation.

In view of this, in the teaching goal of "English syllabus" (revised probation edition) revised in 2000, the junior middle school proposes to "find out something related to cultural difference" and "obtain the ability to appliance English tentatively"; The high school proposes "promotes to know more about foreign cultures, especially those of English speaking countries", "raise the ability to use English communication tentatively". "The Standard of English course" which Chinese Ministry of Education makes in 2001(the experiment draft), add that the item of "culture" is required. Among them "cultural knowledge and preliminary communication ability" are also mentioned. All these have offered us abundant of policy base on studying the subject probing into and increase the contents of culture to English teaching.

\section{Which CONTENTS OF CUlture SHOUld BE AdDED?}

In brief, two major aspects should be included. The first is the cultural factors that influence the semantics; the second is the cultural factors that influence the pragmatics.

\section{A. The Culture Factors that Influence the Semantics.}

Some English words imply certain cultural intensions. If one does not understand these words and hoping to guess their meaning from the word itself according to Chinese culture, he will certainly make mistakes. The following are some examples.

"Adult books" literally means "books for the adults". In the western countries, many books, periodicals and videotapes are usually marked with the age bracket that can read or watch them. Generally the age bracket can be divided into three sections: 16 years old, 18 years old and grown up. Adult books are only served for adults because they include obscene and pornographic contents.

"Blue Monday" mean "depressed Monday". In English, "blue" usually indicates "melancholy", "depressed", and "unhappy". After the happy weekend, Monday arrives. The adults need to begin their work and the children need to go to school. The spirit will no doubt become worse naturally. The similar word has "in the blues", which means depressed. In the culture of Chinese, "blue" does not have this kind of meaning.

"Busy boy" is a compound word. Here "boy" refers to some certain kinds of people, and here "busy" have a cultural intension. Therefore this compound word possesses a new meaning--people who always likes to interfere others' things". Make sure to keep in mind not to comprehend the compound words by putting two simple words` meaning together. There are some other examples:

In some English dictionaries, some English words have the commendatory sense, derogatory sense or the neutral sense. Because there are differences between Chinese culture and western culture, the meanings they each choose are not the same. While understanding and using these words, people should pay more attention to this aspect.

In Chinese, "aggressive" has a derogatory sense and it is used to describe someone who "is apt or ready to attack, quarrelsome. On the contrary, in English it is used to describe those who are not afraid of gossips and keeping ahead.

"Dragon" in Chinese is a commendatory word, which means "successor", "lively and vigorous", "full of life and energy"; But native English speakers treat dragon as an evil symbol and the bizarre entity of fierce and cruelty. So it is often used to frighten the crying children.

The Chinese meaning of "intellectual" is "brain worker with certain science and culture knowledge". It can be divided into two kinds: general intellectual and high level intellectual. It is a commendatory term. In English "intellectual" contains two meanings-- "clever, full of wisdom" and "only probes into the theory but can do nothing to the practical problems". So it implies the derogatory sense.

"Peasant" in Chinese means "people work in the field" and it is a commendatory term. For example: Learn from lower-middle peasants. English gives "peasant" a derogatory sense. It always refers to "people form the countryside", or "people have rough refined manners". The "peasant" we always mentioned is relatively close to the word "farmer" in English.

\section{B. The Cultural Factors that Influence the Language Uses.}

As there are differences existed in many aspects such as values, mode of thinking, moral standard and social etiquette between Chinese culture and western culture, these differences certainly will influence the application of English and formed different cultural stipulations and speaking stipulations. While people are talking, they always follow their own ways of speaking automatically. At the same time, they will understand others in his own way and respond to it. This is why some usages of words appeared to be false in cross-cultural communication. And it is the major obstructions during the communication.

As Chinese culture "regard colony as the center" and the western culture "regard individual as the center" are different from each other on the value system, they have different attitudes towards other people's concern about them. Chinese praise highly on caring about the group, caring about the others and taking pleasure in helping people. On the 
contrary, Americans and British men emphasize self-confidence. They live on by themselves and bear responsibility of themselves. So they don't need the others to concern too much about them. The following instances can show these two kinds of different attitudes obviously.

Chinese culture sings high praise of "benevolence, justice, good manners, intelligence, honesty and modesty". "Modesty makes one progress, pride makes one lags behind". So most of the Chinese are implicit, introversive and regard modest as honor. The western culture, such as those of Great Britain and America are emphasized the culture which regard individual as the center. They advocate obtaining success by themselves. So they are self-confident and willing to display themselves.

Therefore, the above two kinds of people have obvious different attitudes towards compliments. According to the "modest principle", Chinese will refuse and deny the compliment. According to "polite principle", British men and Americans will agree and accept the compliment.

\section{How to AdD CUltural CONTENTS TO ENGLiSh TEACHING?}

First of all, we should believe that various kinds of cultures in the world are equal to each other. As long as they can exist and be accepted, it is proved that they both have its advantages and disadvantages. So, we can't say that this culture is better or worse than that one. Just because there are different kinds of cultures in the world, the world is so colorful and beautiful. While we are trying to promote and develop Chinese splendid culture, we should try to get familiar with the culture of other countries and inherit their advantages. By doing this, we will form an advanced culture that suit for Chinese conditions and develop with the rest of world.

Secondly, while making teaching target for a unit or a class, besides deciding the educating points and language points, the teacher should decide the culture contents that the students should know. The choice of cultural points that to be taught in the class are mainly revolve around the cultural contents that will influence the meaning and usages of the language. These cultural points include the cultural intensions that will influence the meaning of the words; cultural backgrounds that imply in the language; the names of people, places of cultural intension; and the grammatical rules that are influenced by culture.

Thirdly, the infiltration of cultural knowledge should be carried on with other practices, making them get along swimmingly with each other and combining organically. By doing this can not only help the students to understand the language accurately and deeply, but also give the language flesh and blood and make the abstractly stiff language symbol alive. Then English teaching maybe filled with enough information and become more interesting and colorful.

Finally, in order to include cultural knowledge in English teaching, teachers must find the culture to be mentioned at first, then he should develop the ability to explain them. This is to put forward higher request to the teachers. They are required not only to have accurate themselves with sturdy English language basic knowledge, but also have high artistic appreciation. They should understand the culture of China; they should be familiar with those of other countries, especially the culture of English speaking countries; they should find out the differences between the Chinese and Western culture; they should know about the cultural influences on the semantics and usage of the language. In the hope of managing to do the above, three suggestions are put forward here:

English teachers should learn to improve his own artistic appreciation by himself and enlarge his own cultural knowledge;

Enhance the status of the two courses - "Introduction to Great Britain and America" and "Culture of Great Britain and America" in higher teacher education and try to improve the contents of the courses and the teaching method;

The linguists should encourage the more foreign language educators to study the relations between culture and language, culture and communication, culture and foreign language teaching; to offer more research results for the content of culture that added into the foreign language teaching.

\section{REFERENCES}

[1] Lian shuneng. (1993). A Comparison of English and Chinese. Beijing: Higher Education Press.

[2] Wang fuxiang \& Wu hanying. (1994). Culture and language. Beijing: Foreign language teaching and studying Press.

[3] Hu wenzhong. (1990). Study the selected readings in cross-cultural communication. Hunan: Educational publishing house of Hunan.

[4] Barry Tomalin \& Susan Stemplesk. (1993). Cultural Awareness. New York: Oxford University Press.

[5] Hu wenzhong. (1995). Great Britain and America's culture dictionary. Beijing: Foreign Language Teaching and Research Publishing House.

Yanping Huang was born in Guangxi, China in 1980. She received her M.A. degree in journalism from Guangxi University, China in 2007. She is currently a lecturer in Dezhou University, Shandong, China. 